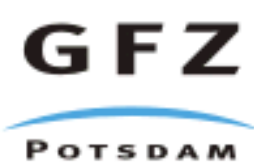

Originally published as:

Sasgen, I., Martinec, Z., Fleming, K. (2007): Regional ice-mass changes and glacial-isostatic adjustment in Antarctica from GRACE. - Earth and Planetary Science Letters, 264, 3-4, 391401

DOI: 10.1016/j.epsl.2007.09.029. 


\title{
Regional ice-mass changes and glacial-isostatic adjustment in Antarctica from GRACE
}

\author{
Ingo Sasgen ${ }^{1}, Z_{\text {deněk Martinec }}^{1,2}$ and Kevin Fleming ${ }^{1}$
}

${ }^{1}$ Department of Geodesy and Remote Sensing, GeoForschungsZentrum Potsdam, Telegrafenberg A17, D-14473, Potsdam, Germany. (sasgen@gfz-potsdam.de)

${ }^{2}$ Department of Geophysics, Faculty of Mathematics and Physics, Charles University, V Holešovičkách 2, Praha, Czech Republic. (zm@karel.troja.mff.cuni.cz)

Keywords: Antarctica; GRACE; mass balance; glacial-isostatic adjustment;

\section{Abstract}

We infer regional mass changes in Antarctica using ca. 4 years of Gravity Recovery and Climate Experiment (GRACE) level 2 data. We decompose the time series of the Stokes coefficients into their linear as well as annual and semi-annual components by a least-squares adjustment and apply a statistical reliability test to the Stokes potential coefficients' linear temporal trends. Mass changes in three regions of Antarctica that display prominent geoid-height change are determined by adjusting predictions of glacier melting at the tip of the Antarctic Peninsula and in the Amundsen Sea Sector, and of the glacial-isostatic adjustment (GIA) over the Ronne Ice Shelf. We use the GFZ RL04, CNES RL01C, JPL RL04 and CSR RL04 potential-coefficient releases, and show that, although all data sets consistently reflect the prominent mass changes, differences in the mass-change estimates are considerably larger than the uncertainties estimated by the propagation of the GRACE errors. We then use the bootstrapping method based on the four releases and six time intervals, each with 3.5 years of data, 
to quantify the variability of the mean mass-change estimates. We find $95 \%$ of our estimates to lie within 0.08 and $0.09 \mathrm{~mm} /$ a equivalent sea-level (ESL) change for the Antarctic Peninsula and within 0.18 and $0.20 \mathrm{~mm} / \mathrm{a}$ ESL for the Amundsen Sea Sector. Forward modelling of the GIA over the Ronne Ice Shelf region suggests that the Antarctic continent was covered by 8.4 to $9.4 \mathrm{~m}$ ESL of additional ice during the Last-Glacial Maximum (ca. 22 to 15 ka BP). With regards to the mantle-viscosity values and the glacial history used, this value is considered as a minimum estimate. The mass-change estimates derived from all GRACE releases and time intervals lie within ca. 20\% (Amundsen Sea Sector), 30\% (Antarctic Peninsula) and 50\% (Ronne Ice Shelf region) of the bootstrap-estimated mean, demonstrating the reliability of results obtained using GRACE observations. 


\section{Introduction}

The determination of the Earth's gravity field at regular time intervals by the Gravity Recovery and Climate Experiment (GRACE) allows the investigation of mass movement within the Earth system (e.g. Tapley et al., 2004). GRACE consists of two low-orbiting satellites in the same near-polar orbit, accurately measuring their separation (ca. $200 \mathrm{~km}$ ) by a $k$-band ranging system. These data, together with GPS, accelerometer and star-camera measurements (GRACE Level 1 data), are used to solve for the spectral representation of the Earth's gravitational potential or Stokes potential coefficients at approximately monthly time intervals (GRACE Level 2 data).

The largest contribution to the gravity field's temporal variability arises from the seasonal redistribution of water associated with hydrological processes. In addition, the increasing length of the GRACE time series (currently ca. 4 years) allows secular changes in the gravity field to be inferred with increasing reliability. Over land, this secular trend is mainly induced by changes in the mass of ice sheets and glaciers and by the inflow of mantle material into regions of former glaciation arising from the glacial-isostatic adjustment (GIA) following the Last-Glacial Maximum (LGM, ca. 22 to $15 \mathrm{ka} \mathrm{BP})$. Other sources of long-term changes include, for example, imbalances in the hydrological cycle and processes in the Earth's deep interior.

Within this context, GRACE observations have been employed to determine the mass balance of polar ice sheets by mainly using the following three approaches. The first, basin averaging, is commonly applied to determine average mass changes in prede- 
fined geographical regions, for example drainage basins (e.g. Swenson \& Wahr, 2002; Velicogna \& Wahr, 2005; Ramillien et al., 2006; Velicogna \& Wahr, 2006). This approach can be optimized with respect to the expected signal and the influence of observational noise, such as far-field signals or the increasing uncertainty associated with GRACE coefficients of higher spherical-harmonic degree and order. Often, forward modelling is applied in estimating the signal loss due to filtering. An alternative method is based on simulations or forward modelling of the mass change of interest using independent geophysical information (e.g. Chen et al., 2006a). Depending upon the nature of the problem, different methods of adjusting the forward models to the GRACE gravity-field solutions are used. The relationship between the changes in the gravitational potential and the sources of mass change is given by the forward models. In contrast, the third approach determines local mass concentrations directly using $k$-band and other GRACE Level 1 data, together with a priori information concerning the geometry and location of the mass changes under consideration (e.g. Luthke et al., 2006). Compared to the first two approaches, its main advantage is that regionally a higher spatial resolution is achieved. Also, the resulting distribution of surface masses do not require additional calibration.

Despite using similar or identical sets of GRACE coefficients, the various approaches have produced significantly different estimates of secular ice-mass change in the polar regions, with their equivalent sea-level (ESL) change ranging, for example, for the Greenland Ice Sheet from $0.23 \pm 0.06$ (Velicogna \& Wahr, 2005) to $0.54 \pm 0.05 \mathrm{~mm} / \mathrm{a}$ ESL (Chen et al., 2006b) and for the Antarctic Ice Sheet from $0.14 \pm 0.09$ (Ramillien et al., 
2006) to $0.38 \pm 0.20 \mathrm{~mm} / \mathrm{a}$ ESL (Velicogna \& Wahr, 2006). For Antarctica, a large cause of the discrepancy between these estimates is the uncertainty in the contributions from GIA.

This paper aims to quantify the most prominent glacier melting and the GIA in Antarctica using the second approach. We refine the previous study of Chen et al. (2006a) by a noise reduction strategy applied to the GRACE data and extend their investigation by simultaneously considering three regions of prominent geoid-height change shown in Figure 1. In contrast to previous studies, we estimate the GIA Fig. 1 signal from the GRACE observations and do not apply an a priori GIA correction. Also, we assess the robustness of our mass-change estimates with respect to the different GRACE releases and the observational period chosen by the application of the bootstrap method. 


\section{Geoid-height change over Antarctica from GRACE}

We investigate four independent time series of the GRACE Stokes potential coefficients that describe the gravity-field changes mainly occurring over land (GSM Level 2 data): GFZ RL04 (Flechtner, 2007), JPL RL04 (Watkins \& Dah Ning, 2007), CSR RL04 (Bettadpur, 2007a) of the GRACE Science Data System (SDS) centers and CNES RL01C (Biancale et al., 2006, http://bgi.cnes.fr:8110/). The solutions of the SDS centers are unconstrained determinations of the gravity field at approximately monthly time intervals. The solutions of the CNES RL01C represent moving averages of three 10-day solutions and were computed using a regularization method. This method allows the determination of the gravity field during periods of low groundtrack coverage that is during resonances in the satellites' orbit and the Earth's rotation. The releases contain at least 48 months of data, respectively, and represent the processing centers' latest gravity-field solutions. In order to homogenize the temporal coverage of the data sets, only solutions between January 2003 and December 2006 are used. Although the solutions include the same GRACE Level 1 data (Bettadpur, 2007b), we consider them as independent representations of the gravity field, since the individual processing strategies, e.g. the choice of background and de-aliasing models, induce differences in the gravity fields that are above the expected GRACE uncertainty.

We decompose the time series of the Stokes potential coefficients into their linear as well as annual and semi-annual components by a least-squares adjustment, assuming 
constant variances over time. Using the Student's $t$-test statistic, we set to zero the resulting linear trend terms $x_{j m}^{\mathrm{o}}$ for the time series of each coefficient of sphericalharmonic degree $j$ and order $m>25$ not exhibiting a statistically significant linear trend at a confidence level of $99 \%$. The minimum of the degree power of unconstrained gravity-field solutions at $j \approx 25$ indicates that coefficients of lower degrees and orders are signal dominated and do not require filtering (e.g. Sasgen et al., 2006). In turn, the significant deviation of the degree power of constrained and unconstrained solutions for $j>25$ suggests that noise reduction should be applied above this degree and order.

The noise reduction strategy applied can be summarized as $y_{j m}^{\mathrm{p} \mid \mathrm{o}}=x_{j m}^{\mathrm{p} \mid \mathrm{o}} s_{j m}$, where $y_{j m}^{\mathrm{p} \mid \mathrm{o}}$ are the filtered coefficients of the predicted|observed temporal linear trend $x_{j m}^{\mathrm{p} \mid \mathrm{o}}$, respectively, and $s_{j m}$ represents the statistical filter that is 1 if the trend $x_{j m}^{\mathrm{o}}$ is statistically significant, otherwise it is $0\left(s_{j m}=1\right.$ for $\left.j, m \leq 25\right)$. According to this criterion, we omit, for example, a number of the near-sectorial coefficients $(j \approx m)$, since these are degraded by the satellites' less dense across-track sampling, resulting in the often discussed north-south striping (Swenson \& Wahr, 2006). This degradation is also reflected in the coefficients' large stochastic variability when compared to their inferred temporal linear trend. Additional spatial smoothing of the gravity fields is not applied.

The higher-degree and -order coefficients of the constrained CNES RL01C solutions contain less noise than those of unconstrained solutions due to the Kaula regularization method applied during the CNES processing. This regularization stabilizes the 
fluctuations in the higher spectral range by constraining the solution to the mean field, which allows an improvement to the signal-to-noise ratio by weighing more the better-quality data (Lemoine et al., 2007). In the spatial domain, the regularization results in smoother and less noisy gravity fields. As mentioned above, a comparison of the degree-power spectra of unconstrained and the constrained CNES RL01C solutions indicates that this a priori noise reduction is effective for coefficients with $j>25$. Hence, for coefficients in this spectral range, we estimate an equivalent $a$ posteriori noise reduction that is then applied to the prediction when investigating the CNES RL01C solutions. The filtering procedure used is similar to Wiener optimal filtering (e.g. Seo \& Wilson, 2005; Sasgen et al., 2006) and it involves the ratio of the degree power of the CNES RL01C trend and the degree power of the unconstrained GFZ RL04 trend. In general, the application of this additional smoothing filter to the prediction is necessary to derive unbiased mass-change estimates from constrained gravity-field solutions, such as the CNES RL01C.

We also confine our investigation to the Stokes coefficients with $j, m \geq 12$ to reduce the long-wavelength signal in the GRACE data arising from mass changes in the farfield with respect to Antarctica and from the Earth's deep interior. The removal of these long wavelengths also reduces the overlap of signals from the individual regions. This limit is determined by calculating the degree correlation of the predicted geoidheight change over Antarctica described in the following section and the GRACE observations (e.g. Sasgen et al., 2007). Figure 2 shows that the degree correlation for Fig. 2 all releases is statistically significant for $j \geq 12$ (the $95 \%$ confidence limit is indicated 
by the dashed line).

It should be mentioned, however, that the geoid-height change induced by mass changes of small spatial scales is not only reflected by coefficients of higher degrees and orders, and vice versa. Therefore, it is necessary to reconsider the coefficients of the lower degrees and orders that were omitted during the adjustment procedure in the mass-change models in order to obtain meaningful mass-change estimates.

Figure 3 shows the resulting rate of geoid-height change over Antarctica as inferred from the four GRACE releases considered. All releases show three prominent anomalies that are associated with known mass change processes, namely at the tip of the Antarctic Peninsula and in the Amundsen Sea Sector, where rapid glacier melting observed by other methods (e.g. laser altimetry) induces a negative rate of geoid-height change, and over the Ronne Ice Shelf (West Antarctica), where the GIA-induced inflow of mantle material following the retreat of the Antarctic Ice Sheet after the LGM causes an increase in the geoid height. In the following, we adjust the mass-change models for these three regions with respect to the noise-reduced GRACE observations. The source of the distinct positive geoid-height change in East Antarctica (centered ca. $50^{\circ} \mathrm{E} ; 70^{\circ} \mathrm{S}$ ) is not identified and will therefore be excluded from this investigation.

It should be noted that the inferred rates of geoid-height change shown in Figure 3 may differ due to the noise-reduction function $s_{j m}$, which is specific for each individual GRACE release. This will be accounted for by applying each reduction to the masschange models. The remaining variability is due to observational uncertainties in 
the GRACE releases and the slightly different months of gravity-field determination considered and will be used to assess the robustness of our mass-change estimates. 


\section{Modeled geoid-height change due to present-day ice-mass changes and GIA}

The geoid-height change over Antarctica is predicted using a viscoelastic earth model subjected to surface-mass changes occurring in selected Antarctic drainage basins and to the glacial history of the entire ice sheet for the last glacial cycle. The predicted geoid-height change $x_{j m}^{\mathrm{p}}$ can be expressed as

$$
x_{j m}^{\mathrm{p}}(s)=\frac{R^{2}}{g_{0}} \sum_{j} q_{j}(s) \frac{4 \pi}{2 j+1} \sum_{m} \sigma_{j m}(s) Y_{j m},
$$

where $R$ is the Earth's radius, $g_{0}$ is the normal gravity at the Earth's surface, $Y_{j m}$ are fully normalized scalar spherical-harmonic functions, $\sigma_{j m}$ are the spherical-harmonic expansion coefficients of surface-mass change, $s$ is the Laplace variable, and $q_{j}$ are the viscoelastic surface-load Love number in the Laplace domain for a specified viscosity distribution (e.g. Wu \& Peltier, 1982). For quasi-instantaneous mass variations $(s \rightarrow$

$0)$, such as present-day ice-mass changes, $q_{j}$ approaches the surface-load elastic Love numbers.

Altimetry and Interferometric Synthetic Aperture Radar (InSAR) measurements of the Antarctic Ice Sheet indicate that there are two regions experiencing prominent ice-mass change: the tip of the Antarctic Peninsula, where particularly the glaciers Hektoria/Green/Evans, Jorum, Crane, Flask, Leppard and Drygalski were observed to rapidly retreat following the collapse of the Larsen B Ice Shelf in March 2002, resulting in an estimated mass loss of ca. 0.07 mm/a ESL (Rignot et al., 2004; Scambos et al., 
2004) and the Amundsen Sea Sector, in particular the glaciers Pine Island, Thwaites, Smith and Kohler, with an estimated total loss of ca. $0.24 \mathrm{~mm} / \mathrm{a}$ ESL (Thomas et al., 2004). Other drainage basins of the ice sheet appear to be almost in balance (e.g. Remy \& Frezzotti, 2006), except for Ice Stream C (ca. 230 E; $\left.85^{\circ} \mathrm{S}\right)$, West Antarctica, which is observed to be accumulating mass at a rate of $-0.05 \mathrm{~mm} / \mathrm{a}$ ESL due to a decrease in its flow velocity (Rignot \& Thomas, 2002). The geoid-height change associated with these mass changes is calculated according to equation (1) assuming an elastic earth model.

The GIA-induced geoid-height change is calculated according to equation (1) using a viscoelastic earth model combined with the glacial history of Huybrechts (2002). The Huybrechts (2002) reconstruction is based on results from a thermomechanical ice-sheet model that simulates the variation in the volume and extent of the Antarctic Ice Sheet. The temporal evolution used here is linearly interpolated from four snapshots of the state of the ice sheet at 15, 7, 4 ka BP and at present. Its main characteristic is the late deglaciation of the Ronne Ice Shelf region, which continues until today. In agreement with glaciological and geomorphologic evidence (e.g. Bentley, 1999; Anderson et al., 2002; Ivins \& James, 2005), the reconstruction also features the largest reduction of ice mass in Antarctica around the region of the Ronne Ice Shelf. This, in turn, leads to the largest GIA-induced geoid-height change signal consistent with that predicted using the geomorphologic reconstruction of Lambeck \& Chappell (2001). Although the glacial history of Peltier (2004) based on globally distributed paleo sea-level indicators also requires a rather late initiation of Antarctic 
deglaciation (ca. $15 \mathrm{ka} \mathrm{BP}$ ), it includes the largest retreat of ice, hence, the largest GIA signal over the Ross Ice Shelf. In this work, we focus on the GIA signal over the Ronne Ice Shelf to adjust the glacial history of Huybrechts (2002), as the predicted GIA signals in the other regions of the Antarctic continent are considerably smaller in magnitude, which is supported by the GRACE observations.

We use a four-layer viscoelastic earth model consisting of an elastic lithosphere of thickness $h_{\mathrm{L}}=100 \mathrm{~km}$, an upper mantle of viscosity $\eta_{\mathrm{UM}}=5.2 \cdot 10^{20} \mathrm{~Pa} \mathrm{~s}$, a lower mantle of viscosity $\eta_{\mathrm{LM}}=5.9 \cdot 10^{21} \mathrm{~Pa}$ s and a fluid core. This viscosity profile corresponds to that determined for Fennoscandia using the relaxation time spectrum derived from regional paleo-shorelines (Martinec \& Wolf, 2005). However, it is also satisfactory when reproducing global sea-level change over the past $20 \mathrm{ka}$, and we therefore consider it to be a global-average earth model also appropriate for the mantle beneath West Antarctica, of which very little is known. However, we also modify the viscosity profile within a plausible range to assess its influence on our mass-change estimates. As a result, we find that changing the viscosity values mainly influences the magnitude of the predicted GIA-induced geoid-height change, while its spatial pattern is retained (not shown here). 


\section{Mass-change estimate}

The predictions representing the geoid-height change over all regions of interest, i. e. the Antarctic Peninsula, the Amundsen Sea Sector and the Ronne Ice Shelf, are filtered by the version of the statistical filter, $s_{j m}$ discussed above, that is adapted to the noise level of the GRACE release under consideration. This is necessary to verify the consistency of the modeled geoid-height change after the noise reduction and avoids biasing the resulting mass-change estimates. For the investigation of the trends inferred from CNES RL01C solutions, the modeled geoid-height changes are additionally smoothed by the spatial-averaging filter described in Section 2.

After filtering, we synthesize the coefficients with $12 \leq j, m \leq 50$ of the predicted and observed geoid-height change, $y_{j m}^{\mathrm{p}}$ and $y_{j m}^{\mathrm{o}}$, to obtain their associated spatial representation, $y_{i}^{\mathrm{p}}$ and $y^{\mathrm{o}}$, respectively. Here, the index $i$ refers to the modeled geoidheight change including the signal over the region of interest, i. e. the Antarctic Peninsula $(i=1)$, the Amundsen Sea Sector $(i=2)$ and the Ronne Ice Shelf region $(i=3)$

We adjust the magnitude of each modeled geoid-height change to fit the GRACE data such that the residual signals over the three areas, $\Omega_{i}, i=1,2,3$ (coordinate rectangles in Figures 1 and 3), are minimized in the $L_{1}$-norm sense. The size of the three adjustment areas is chosen to be consistent with the spatial GRACE resolution of ca. $4^{\circ}$, which is estimated from the signal-to-noise ratio of the degree-power spectrum using the Wiener optimal-filtering approach (Sasgen et al., 2006). The adjustment 
is carried out on a $0.25^{\circ} \times 0.25^{\circ}$ grid. The $L_{1}$ norm is used as it is most sensitive to extreme values, which are, for the GRACE data, the most robust with respect to the remaining observational noise. We include an adjustment area around the peak values of the geoid-height change to assure that the fitting is insensitive to changes in the spatial pattern of the geoid-height change or lateral variations in the positions of the extreme values due to residual noise.

We make use of the cost function $E$ defined as

$$
E:=\sum_{i=1}^{3} \int_{\Omega_{i}}\left\|y^{\mathrm{o}}(\Omega)-y_{i}^{\mathrm{p}}(\Omega) \alpha_{i}\right\|_{L_{1}} d \Omega
$$

which is minimized with respect to the scale factors $\alpha_{i}$. Having determined $\alpha_{i}$, the optimal model of the geoid-height change for Antarctica is given by the scaling and summation of the three geoid-height change models, $y^{\alpha}=\sum_{i=1}^{3} y_{i}^{\mathrm{p}}(\Omega) \alpha_{i}$. The surfacemass change of interest is then determined by using the linear relation between the source of the mass change and the associated variation of the gravitational potential according to equation 1 . This is done by considering the full spectral range of the models of the geoid-height change.

It should be mentioned that even though the adjustment areas $\Omega_{i}$ and peak mass changes are spatially separated, the modeled geoid-height change for each of the three regions will overlap with the other, even after reducing the long-wavelength components of the gravity field. We account for the remaining overlaps by adjusting the models of all three regions simultaneously, as expressed by the summation in equation 2. Also, data outside of the areas $\Omega_{i}$ are not considered when determining the 
scale factors $\alpha_{i}$. 


\section{Uncertainty in the mass-change estimate}

One method used to determine the uncertainty in our mass-change estimates is by the propagation of the variance of the least-squares regression parameters, $\operatorname{var}\left(x_{j m}^{\mathrm{o}}\right)$, to the parameters $\alpha_{i}$. For uncertainties arising from the use of a single GRACE release, we assume no covariances between the linear-trend coefficients. The variance with respect to two spatial coordinates $\Omega_{k, l}$ on the adjustment grid can be expressed by

$$
\operatorname{var}\left(x^{\mathrm{o}}\right)_{k l}=\sum_{j m} Y_{j m}\left(\Omega_{k}\right) \operatorname{var}\left(x_{j m}^{\mathrm{o}}\right) Y_{j m}\left(\Omega_{l}\right)
$$

The variance of the adjustment parameter $\alpha_{i}$ is given by (e.g. Koch, 1999)

$$
\operatorname{var}\left(\alpha_{i}\right)=\frac{\sum_{k l} y_{i}^{\mathrm{p}}\left(\Omega_{k}\right) \operatorname{var}_{k l}\left(x^{\mathrm{o}}\right) y_{i}^{\mathrm{p}}\left(\Omega_{l}\right)}{\left[\sum_{k l} y_{i}^{\mathrm{p}}\left(\Omega_{k}\right) y_{i}^{\mathrm{p}}\left(\Omega_{l}\right)\right]^{2}}
$$

where $y_{i}^{\mathrm{p}}$ denotes the spatial representation of the modeled geoid-height change for the individual regions and $\Omega_{k, l} \in \Omega_{i}$ represent the spatial coordinates within the associated adjustment area.

Another method used to assess the robustness of our results is by conducting a bootstrap estimate (e.g. Efron \& Tibshirani, 1993) of the mean mass change. The bootstrap estimate can be used to infer the statistical properties of a distribution from a small number of samples (ca. 20) on the assumption that each individual sample captures the essential properties of the underlying population. Here, the sample observations are the 24 mass-change estimates for each of the three regions derived from the four GRACE releases using six 3.5 year-long time intervals that are shifted with respect to each other by one month. The first interval is January 2003 to June 2006, 
hence the last time interval is June 2003 to November 2006. For comparison, we also obtain estimates using the full four-year period, January 2003 to December 2006. Shifting the time intervals allows us to assess the stationarity of the signals investigated and the uncertainty that arises from not including other time variations into our model, such as accelerations and longer-term oscillations. We randomly draw a collection of 24 samples from our 24 mass-change estimates and calculate their mean assuming equal probability of each mass-change estimate. The procedure is repeated 1000 times. The resulting distribution of means provides a measure of the uncertainty of the inferred mean mass change, which includes the differences between the GRACE releases and the variations in the temporal linear trend with respect to the observation period.

\section{Results and discussion}

The top of Figure 4 shows the mass-change estimates based on the four-year period Fig. 4 (January 2003 to December 2006) of the GFZ RL04, CNES RL01C, JPL RL04 and CSR RL04 releases; (a) ice loss at the tip of the Antarctic Peninsula and in the Amundsen Sea Sector and (b) mass change of the Antarctic Ice Sheet since LGM, as inferred from the GIA signal over the Ronne Ice Shelf (third region). The values in (b) correspond to the additional ice mass required with respect to the reconstruction of Huybrechts (2002) at 15 ka BP that is necessary to produce the observed geoid-height change over the Ronne Ice Shelf regions, given the earth-model parameters employed 
$\left(h_{\mathrm{L}}=100 \mathrm{~km}, \eta_{\mathrm{UM}}=5.2 \cdot 10^{20} \mathrm{~Pa} \mathrm{~s}\right.$ and $\left.\eta_{\mathrm{LM}}=5.9 \cdot 10^{21} \mathrm{~Pa} \mathrm{~s}\right)$. Here, we assume that the scale factor determined also applies to the other regions of Antarctica with past ice-mass changes described in the glacial history, for example, the region of the Ross Ice Shelf and the Amery Ice Shelf (East Antarctica). The associated error bars are calculated according to equation 3. It is noticeable that the results obtained from the four releases differ significantly, in particular the mass-change estimates derived from the signal over the Ronne Ice Shelf. Similar results using the unfiltered spectral range of the GRACE data indicate that this variability is not a product of the noise reduction applied. In general, the GFZ RL04 and the CSR RL04 give very similar results, compared to which the values of the CNES RL01C are slightly higher, and the values of the JPL RL04 are somewhat lower. This variability in the results with respect to the different releases is probably due to observational uncertainties that are underestimated by the propagated errors. As shown in Figure 3, all releases consistently reflect the predicted geoid-height change and are therefore considered to be appropriate for deriving mass-change estimates.

The bottom of Figure 4 presents the results of the bootstrap estimate. Shown are histograms of 20 equidistant bins that indicate the frequency of each mean masschange estimate. The diamond and bar above each histogram represent the mean of the population and the interval bracketing $95 \%$ of the estimates, respectively. The grey-shaded areas indicate the variability of all 24 underlying mass-change estimates.

For the Antarctic Peninsula, our inferred mean mass change of $0.08 \mathrm{~mm} / \mathrm{a}$ ESL ( \pm ca. $6 \%)$ agrees well with the values determined from radar interferometry $(0.07 \mathrm{~mm} / \mathrm{a}$ ESL; 
Rignot et al., 2004). This is remarkable since the mass change in this region is very localized and is likely to be influenced by mass changes associated with the Antarctic Circumpolar Current. However, we observe that the values for all releases and all six time intervals are bracketed between 0.07 and $0.11 \mathrm{~mm} / \mathrm{a}$ ESL, with most of the CNES RL01C estimates being higher and a slight increase of mass loss for later time intervals. The increasing values for later time intervals indicate a non-stationary process that may, for example, be caused by an acceleration of the melting of glaciers in this region, a period of enhanced melting during the end of 2006, or a long-term mass change in the surrounding ocean.

For the Amundsen Sea Sector, 95\% of our bootstrap estimates of the mean mass change lie between 0.18 and $0.20 \mathrm{~mm} / \mathrm{a}$ ESL, the values of all releases and time intervals ranging between 0.16 and $0.23 \mathrm{~mm} / \mathrm{a}$ ESL. The mass loss for each of the time intervals investigated is nearly constant, meaning that the variability mainly arises from the differences in the releases. Also for this region, the GFZ RL04 and the CSR RL04 produce results which are closest to each other $(\sim \pm 0.01 \mathrm{~mm} / \mathrm{a}$ ESL), while the CNES RL01C and JPL RL04 based estimates are ca. $0.03 \mathrm{~mm} / \mathrm{a}$ ESL higher and lower, respectively. The bootstrap-estimated mean of $0.19 \mathrm{~mm} / \mathrm{a}$ ESL $( \pm 6 \%)$ is considerably lower than the most recent estimate based on aircraft- and satellitelaser altimetry, ca. $0.24 \mathrm{~mm} / \mathrm{a}$ ESL (Thomas et al., 2004), but it is somewhat higher than a previous estimate of $0.17 \pm 0.03 \mathrm{~mm} / \mathrm{a}$ ESL (Rignot \& Thomas, 2002). It is close to the minimum of the range of $0.21 \pm 0.04$ to $0.28 \pm 0.05 \mathrm{~mm} / \mathrm{a}$ ESL presented by Chen et al. (2006a), who investigated using a forward modelling approach the 
constrained CSR RL01C gravity fields. However, our estimate is much lower than the rate of $0.30 \pm 0.06 \mathrm{~mm} / \mathrm{a}$ ESL determined by Ramillien et al. (2006) using the basin-analysis approach and the CNES RL01C release. An explanation for this large deviation is that the authors considered a larger number of West Antarctic glaciers and also applied an a priori GIA correction of $0.06 \mathrm{~mm} / \mathrm{a}$ ESL to the mass-change estimate.

For the Ronne Ice Shelf region, based on the glacial history of Huybrechts (2002) and the earth model parameters used $\left(h_{\mathrm{L}}=100 \mathrm{~km}, \eta_{\mathrm{UM}}=5.2 \cdot 10^{20} \mathrm{~Pa} \mathrm{~s}\right.$ and $\left.\eta_{\mathrm{LM}}=5.9 \cdot 10^{21} \mathrm{~Pa} \mathrm{~s}\right), 95 \%$ of the adjusted models of the GIA-induced geoid-height change suggest that the Antarctic continent was covered by 8.4 to $9.5 \mathrm{~m}$ ESL of additional ice during the LGM. The range of values inferred from all releases and time intervals is 6.1 to $10.8 \mathrm{~m}$, representing a larger variability than the values for the other two regions. A possible explanation is that the ocean tides under the Ronne Ice Shelf may not have been completely removed from the GRACE gravity-field solutions (King et al., 2005; King \& Padman, 2005; Han et al., 2005). The bootstrap-estimated mean mass change is $9.0 \mathrm{~m}$ ESL $( \pm$ ca. $6 \%$ ). It lies in the range of 6.1 to $13.1 \mathrm{~m}$ ESL proposed by Bentley (1999) and largely agrees with the value of $10.1 \mathrm{~m}$ ESL of Ivins \& James (2005). The value corresponds to a maximum rate of geoid-height change over the Ronne Ice Shelf region (ca. $293^{\circ} \mathrm{E} ; 81^{\circ} \mathrm{S}$ ) of $1.5 \mathrm{~mm} / \mathrm{a}$ when synthesizing the full spectral range $(2 \leq j, m \leq 50)$. This rate of geoid-height change is at the lower end of the range predicted by Kaufmann (2002) (ca. 1.5 to $3 \mathrm{~mm} / \mathrm{a}$ ), but it is 2 to 3 times larger than the range of 0.4 to $0.8 \mathrm{~mm} /$ a predicted by Ivins et al. (2001) 
and Ivins \& James (2005).

It should be stated that our interpretation of the GIA signal depends on the assumed earth model, and, to a much greater extent, on the characteristics of the Antarctic deglaciation. The combination of the viscosity profile and glacial history used here results in a rather large GIA signal over the Ronne Ice Shelf, and we therefore consider our value to be a minimum estimate. For example, using higher upper-mantle viscosities of $\eta_{\mathrm{UM}}=6 \cdot 10^{20} \mathrm{~Pa} \mathrm{~s}$ and $\eta_{\mathrm{UM}}=8 \cdot 10^{20} \mathrm{~Pa} \mathrm{~s}$, reduces the magnitude of the GIA signal over the Ronne Ice Shelf. This can be compensated by a ca. $10 \%$ and ca. 15\%, respectively, larger mass change of the Antarctic Ice Sheet since the LGM. In contrast, a reduced upper-mantle viscosity of $\eta_{\mathrm{UM}}=4 \cdot 10^{20} \mathrm{~Pa}$ s suggests a ca. $5 \%$ smaller amount of additional ice during the LGM. The mass-change estimates are not sensitive to the lower-mantle viscosity, because variations in the gravity field that would arise from changing this parameter are important only in the lower spectral range that is not considered.

A similar GIA signal is obtained using the reconstruction of Lambeck \& Chappell (2001), which features ca. 33 m ESL of additional ice at the LGM and a much earlier retreat compared to the glacial history of Huybrechts (2002). This illustrates the ambiguity inherent in the inversion of the GIA signal and emphasizes that additional constraints on the timing of the deglaciation are required. However, the mass-change estimates for the Antarctic Peninsula and the Amundsen Sea Sector are not significantly influenced when the reconstruction of Lambeck \& Chappell (2001) is used, owing it producing an similar GIA signal in Antarctica as the Huybrechts (2002) 
model. 


\section{Conclusions}

We have determined noise-reduced temporal linear trends in geoid-height change over Antarctica from four independent GRACE releases and have fitted these observations by adjusting mass-change models reflecting three regions of prominent ice-mass loss (Antarctic Peninsula and the Amundsen Sea Sector) and GIA (Ronne Ice Shelf region).

We have shown that the mass-change estimates of the GRACE releases differ significantly and that the conventional propagation of GRACE errors underestimates these uncertainties. We have then calculated a bootstrap estimate of the mean mass change based on 24 mass-change estimates, each of which was derived from 3.5 years worth of data, allowing us to assess the robustness of our results.

For the Antarctic Peninsula, the ice-mass loss estimated for all releases and time intervals considered is bracketed between 0.07 and $0.11 \mathrm{~mm} / \mathrm{a}$ ESL, the bootstrapestimated mean mass change being $0.08 \mathrm{~mm} / \mathrm{a}$ ESL ( \pm ca. $6 \%$ ), which agrees with values inferred from radar interferometry (0.07 mm/a ESL; Rignot et al., 2004). For the Amundsen Sea Sector, the ice-mass loss determined is between 0.16 and $0.23 \mathrm{~mm} / \mathrm{a}$ ESL, the bootstrap estimate giving $0.19 \mathrm{~mm} / \mathrm{a}$ ESL $( \pm 6 \%$ ). This is considerably lower than an laser-altimetry measurement of $0.24 \mathrm{~mm} / \mathrm{a}$ ESL(Thomas et al., 2004) and close to the minimum of the previous GRACE-based estimate of Chen et al. (2006a) (0.21 \pm 0.04 to $0.28 \pm 0.05 \mathrm{~mm} / \mathrm{a}$ ESL). We have interpreted the signal over the Ronne Ice Shelf in terms of GIA using a viscoelastic earth model and the glacial history of Huybrechts (2002). For all releases and time intervals, the sig- 
nal suggest a mass change of the Antarctic Ice Sheet since the LGM of between 6.1 and $10.8 \mathrm{~m}$ ESL, the value varying by ca. $15 \%$ for the range of plausible viscosity profiles. The bootstrap estimate of $9.0 \mathrm{~m} \mathrm{ESL} \mathrm{(} \pm$ ca. $6 \%$ ) agrees with the geomorphologic estimate of 6.1 and $13.1 \mathrm{~m}$ ESL by Bentley (1999). We have found that the mass-change estimates for all releases and time intervals lie within ca. 20\% (Amundsen Sea Sector), 30\% (Antarctic Peninsula) and 50\% (Ronne Ice Shelf region) of the bootstrap-estimated mean, demonstrating the reliability of mass-change estimates in Antarctica from GRACE observations.

\section{Acknowledgments}

The first author thanks Christoph Reigber for his continuous support, Erik Ivins for helpful discussions and Detlef Wolf for the improvement to the manuscript. The second author acknowledges support from the Grant Agency of the Czech Republic through Grant No. 205/06/0580. The authors thank Georg Kaufmann and one anonymous reviewer for their constructive comments that have helped to improve the manuscript. 


\section{References}

ADD Consortium, 2000. Antarctica Digital Database, Version 3.0, Database, Manual and Bibliography, Scientific Commitee on Antarctic Research (SCAR), Cambridge.

Anderson, J. B., Shipp, S. S., Lowe, A. L., Wellner, J. S., \& Mosola, A. B., 2002. The Antarctic Ice Sheet during the Last Glacial Maximum and its subsequent retreat history: a review, Quat. Sci. Rev., 21(1-3), 49-70.

Bentley, M. J., 1999. Volume of Antarctic ice at the Last Glacial Maximum, and its impact on global sea level change, Quat. Sci. Rev., 18(14), 1569-1595.

Bettadpur, S., 2007. CSR Level-2 Processing Standards Document for Level-2 Product Release 04, Univ. Texas, Austin.

Bettadpur, S., 2007. Gravity Recovery and Climate Experiment Product Specification Document, Univ. Texas, Austin.

Biancale, R., Lemoine, J.-M., Loyer, S., Bruinsma, S., Perosanz, F., Marty, J.-C., Sarrailh, M., Vales, N., \& Balmino, G., 2006. Monitoring variations of the geoid every 10 days from GRACE and LAGEOS satellite missions, Geophys. Res. Abstr., 8(05546).

Chen, J. L., Wilson, C. R., Blankenship, D. D., \& Tapley, B. D., 2006. Antarctic mass rates from GRACE, Geoph. Res. Lett., 33, L11502.

Chen, J. L., Wilson, C. R., \& Tapley, B. D., 2006. Satellite gravity measurements confirm accelerated melting of Greenland ice sheet, Science, $\mathbf{3 1 3}(5795)$. 
Efron, B. \& Tibshirani, R., 1993. An Introduction to the Bootstrap, Chapman \& Hall, New York.

ESRI, 2003. Digital Chart of the World (DCW), Pennsilvania State University Libraries.

Flechtner, F., 2007. GFZ Level-2 Processing Standards Document for Level-2 Product Release 04, GeoForschungsZentrum Potsdam.

Han, S.-C., Shum, C. K., \& Matsumoto, K., 2005. GRACE observations of $m_{2}$ and $s_{2}$ ocean tides underneath the Filchner-Ronne and Larsen ice shelves, Antarctica, Geoph. Res. Lett., 32, L20311.

Huybrechts, P., 2002. Sea-level changes at the LGM from ice-dynamic reconstructions of the Greenland and Antarctic ice sheets during the glacial cycles, Quat. Sci. Rev., 21, 203-231.

Ivins, E. R. \& James, T. S., 2005. Antarctic glacial isostatic adjustment: A new assessment, Antarctic Sci., 17(4), 541-553.

Ivins, E. R., James, T. S., Wu, X., Raymond, C. A., \& Yoder, C. F., 2001. Temporal geoid of a rebounding Antarctica and potential measurement by the GRACE and GOCE satellites, Gravity, Geoid and Geodynamics 2000, Springer, Heidelberg.

Kaufmann, G., 2002. Predictions of secular geoid changes from late Pleistocene and Holocene Antarctic ice-ocean mass imbalance, Geophys. J. Int., 148, 340-347. 
King, M. A. \& Padman, L., 2005. Accuracy assessment of ocean tide models around Antarctica, Geoph. Res. Lett., 32, L23608.

King, M. A., Penna, N. T., Clarke, L., \& King, E. C., 2005. Validation of ocean tide models around Antarctica using onshore GPS and gravity data, J. Geoph. Res., 110(B8), B08401.

Koch, K. R., 1999. Parameter Estimation and Hypothsis Testing in Linear Models, Springer, New York.

Lambeck, K. \& Chappell, J., 2001. Sea-level change throughout the last-glacial cycle, Science, 292(5517), 679-686.

Lemoine, J.-M., Bruinsma, S., Loyer, S., Biancale, R., Marty, J.-C., Perosanz, F., \& Balmino, G., 2007. Temporal gravity field models inferred from GRACE data, Adv. Space Res..

Luthke, S. B. amd Zwally, H. J., Abdalati, W., Rowlands, D. D., Ray, R. D., Nerem, R. S., Lemoine, F. G., McCarthy, J. J., \& Chinn, D. S., 2006. Recent Greenland ice mass loss by drainge system from satellite gravity observation, Science Express.

Martinec, Z. \& Wolf, D., 2005. Inverting the Fennoscandian relaxation-time spectrum in terms of an axisymmetric viscosity distribution with a lithosperic root, J. Geodyn., 39(2), 143-163.

Peltier, W. R., 2004. Global glacial isostasy and the surface of the ice-age earth: the ICE5G (VM2) model and GRACE, Ann. Rev. Earth Planet. Sci., 32, 111-149. 
Ramillien, G., Lombard, A., Cazenave, A., Ivins, E. R., Llubes, M., Remy, F., \& Biancale, R., 2006. Interannual variations of the mass balance of the Antarctica and Greenland ice sheets from GRACE, Global Planet. Change, 53(3), 198-208.

Remy, F. \& Frezzotti, M., 2006. Antarctica ice sheet mass balance, C. R. Geosci., 338, 1084-1097.

Rignot, E. \& Thomas, R. H., 2002. Mass balance of polar ice sheets, Science, 297(5586), 1502-1506.

Rignot, E., Casassa, G., Gogineni, P., Krabill, W., Rivera, A., \& Thomas, R., 2004. Accelerated ice discharge from the Antarctic Peninsula following the collapse of Larsen B ice shelf, Geophys. Res. Lett., 31(18), L18401.

Sasgen, I., Martinec, Z., \& Fleming, K., 2006. Wiener optimal filtering of GRACE data, Stud. Geophys. Geod., 50(4), 499-508.

Sasgen, I., Martinec, Z., \& Fleming, K., 2007. Wiener optimal combination and evaluation of GRACE gravity fields over antarctica, J. Geoph. Res., B(112), B04401.

Scambos, T. A., Bohlander, J. A., Shuman, C. A., \& Skvarca, P., 2004. Glacier acceleration and thinning after ice shelf collapse in the Larsen B embayment, Antarctica, Geophys. Res. Lett., 31(18), L18402.

Seo, K.-W. \& Wilson, C. R., 2005. Simulated estimation of hydrological loads from GRACE, J. Geodesy, 78, 442-456.

Swenson, S. \& Wahr, J., 2002. Methods for inferring regional surface-mass anomalies 
from Gravity Recovery and Climate Experiment (GRACE) measurements of timevariable gravity, J. Geophys. Res., 107(B9).

Swenson, S. \& Wahr, J., 2006. Post-processing removal of correlated errors in GRACE data, Geophys. Res. Lett., 33(8), L08402.

Tapley, B., Bettadpur, S., Watkins, M., \& Reigber, C., 2004. The gravity recovery and climate experiment: Mission overview and early results, Geophys. Res. Lett., 31(9).

Thomas, R., Rignot, E., Casassa, G., Kanagaratnam, P., Acuña, C., Akins, T., Brecher, H., Frederick, E., Gogineni, P., Krabill, W., Manizade, S., Ramamoorthy, H., Rivera, A., Russel, R., Sonntag, J., Swift, R., Yungel, J., \& Zwally, J., 2004. Accelerated sea-level rise from West Antarctica, Science, 306(5694), 255-258.

Velicogna, I. \& Wahr, J., 2005. Greenland mass balance from GRACE, Geophys. Res. Lett., 32(18), L18505.

Velicogna, I. \& Wahr, J., 2006. Measurements of Time-Variable Gravity Show Mass Loss in Antarctica, Science, 311(5768), 1754-1756.

Watkins, M. \& Dah Ning, Y., 2007. JPL Level-2 Processing Standards Document for Level-2 Product Release 04, Jet Propulsion Laboratory, Pasadena.

Wu, P. \& Peltier, W. R., 1982. Viscous gravitational relaxation, Geophys. J. Roy. Astr. S., 70, 435-486. 
Fig. 1 Map of Antarctica based on the Antarctica Digital Database (ADD Consortium, 2000) and the Digital Chart of the World (ESRI, 2003). We focus our investigation to the regions delimited by the coordinate rectangles (solid lines), namely (1) the tip of the Antarctic Peninsula, (2) the Amundsen Sea Sector and (3) the Ronne Ice Shelf region.

Fig. 2 Degree correlation between the predicted and observed rate of geoid-height change over Antarctica for GFZ RL04 (circles), CNES RL01C (asterisk), JPL RL04 (diamonds) and CSR RL04 (crosses). The $95 \%$ significance level is indicated by the dashed line. The investigation is limited to the Stokes potential coefficients of $12 \leq j, m \leq 50$, for which all releases show a significant correlation with the geoidheight change predicted by the mass-change models employed.

Fig. 3 Rate of geoid-height change over Antarctica determined from (a) GFZ RL04, (c) CNES RL01C, (e) JPL RL04 and (g) CSR RL04, and the associated adjusted geoid-height change resulting from present-day ice-mass changes and GIA for (b) GFZ RL04, (d) CNES RL01C, (f) JPL RL04 and (h) CSR RL04. The three coordinate rectangles (solid lines) indicate the areas used for the adjustment of the geoid-height change models, namely the Antarctic Peninsula, the Amundsen Sea Sector and the Ronne Ice Shelf region. The cut-off degrees are $j_{\min }=12$ and $j_{\max }=50$.

Fig. 4 Mass changes in Antarctica as inferred from the four GRACE releases. (a) Present-day ice-mass changes along the Antarctic Peninsula (i.e. Hektoria/Green/Evans, Jorum, Crane, Flask, Leppard and Drygalski glaciers) and the Amundsen Sea Sector 
(i.e. Pine Island, Thwaites, Smith and Kohler glaciers) and (b) mass change of Antarctic Ice Sheet since the LGM. Top: Mass-change estimates and associated propagated errors for the four GRACE releases considering the four-year period January 2003 to December 2006. Bottom: Histogram of bootstrap-estimated mean mass changes. The grey-shaded area indicate the minimum and maximum mass changes obtained using all GRACE releases and time intervals. 


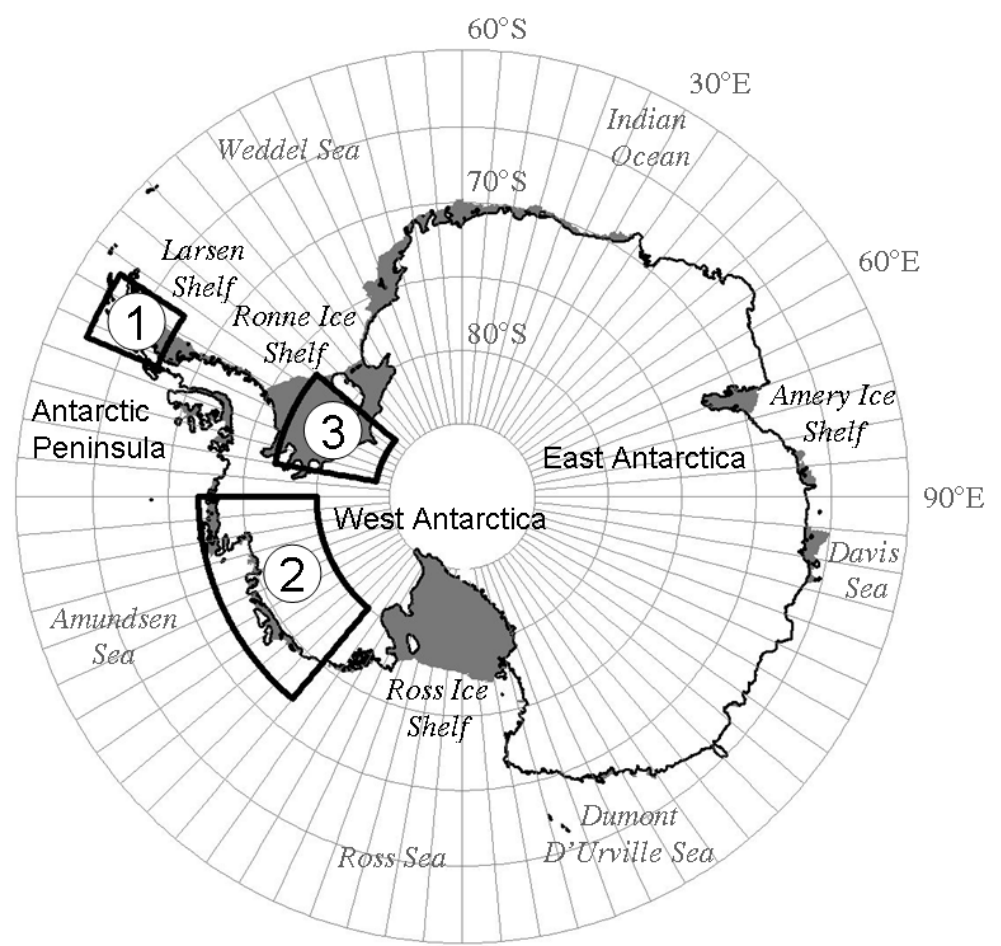

Figure 1: 


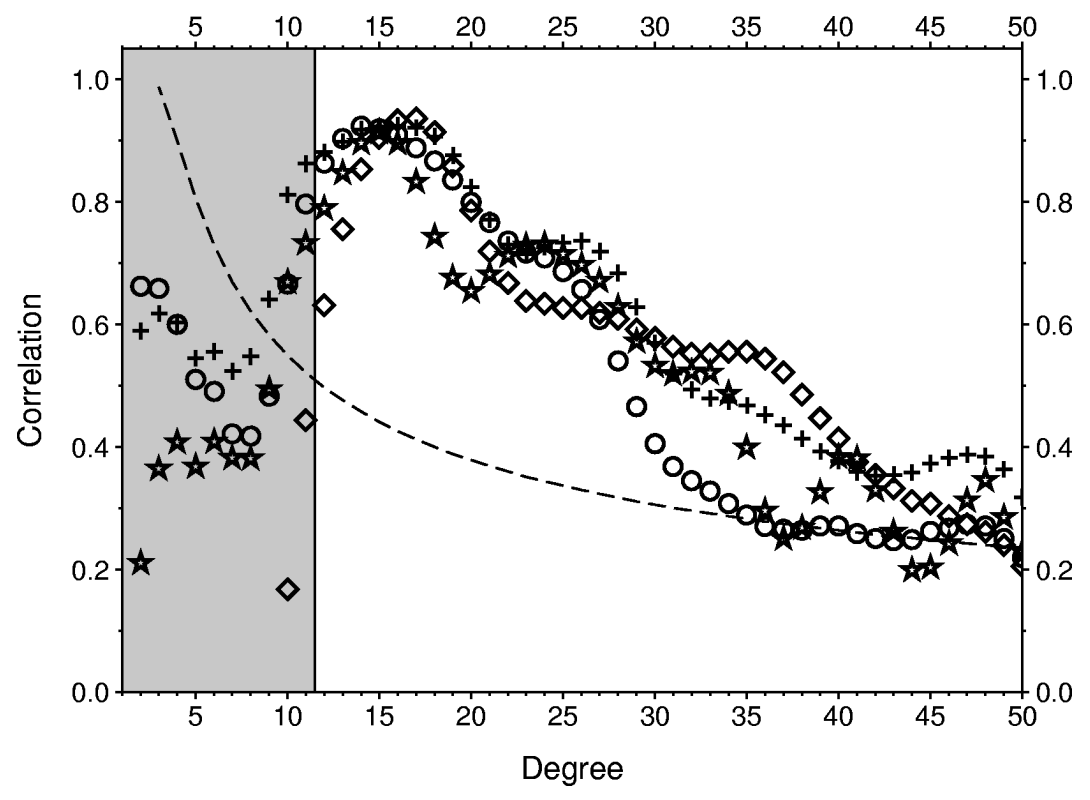

Figure 2: 
a)
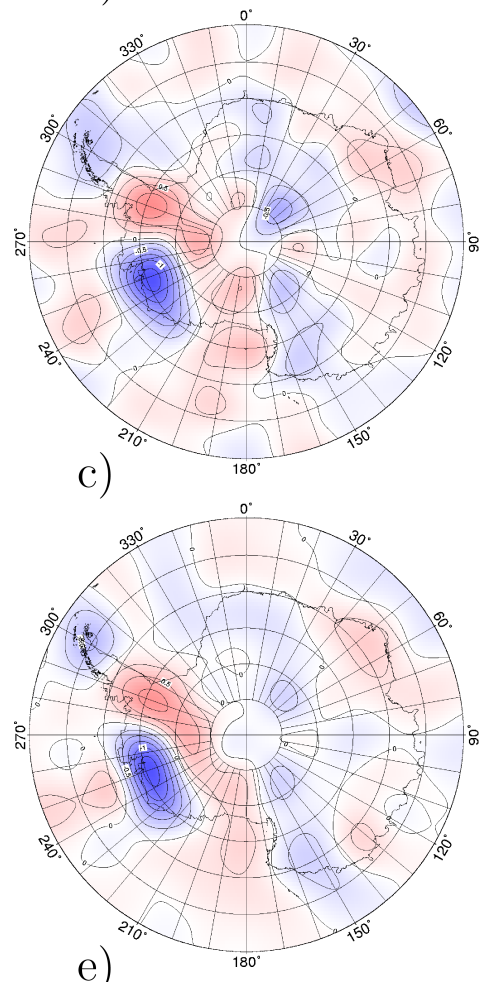

e)

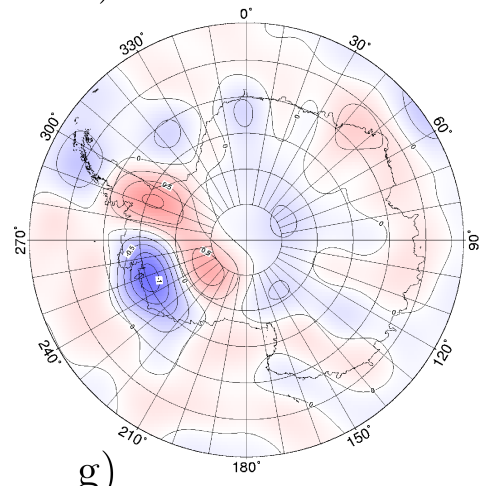

g)

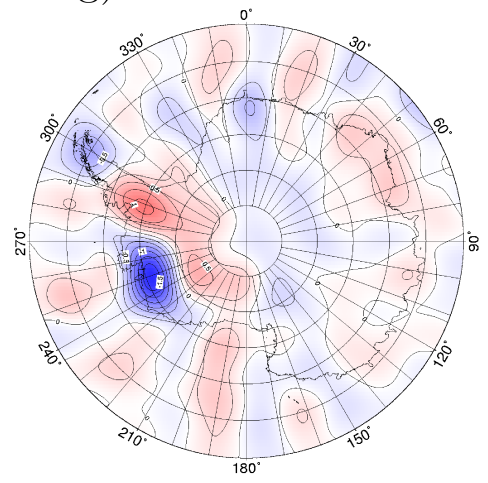

b)

d)

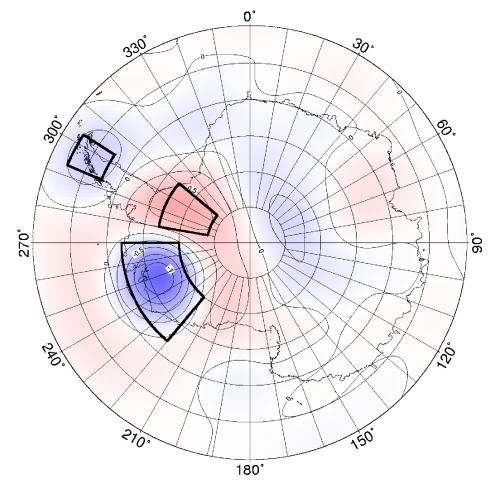

f)

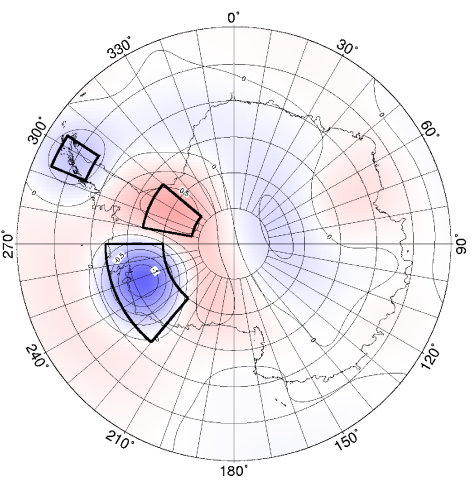

h)
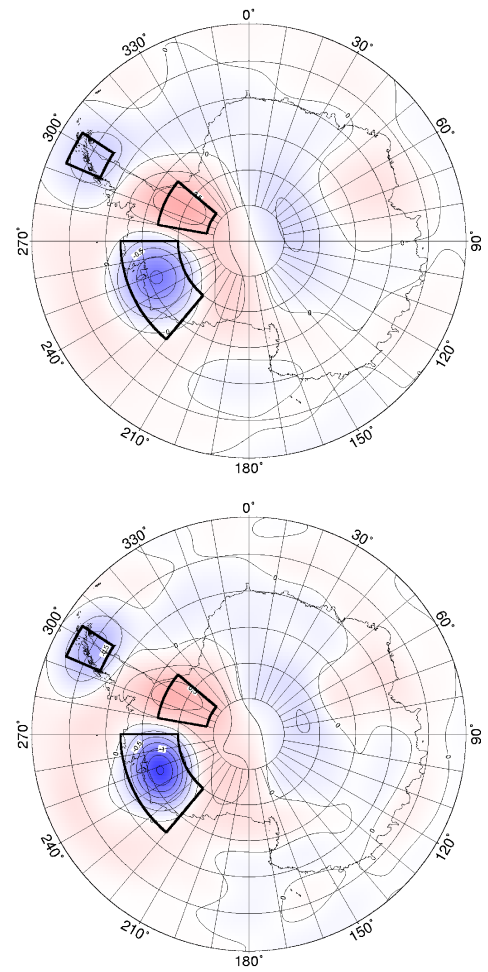

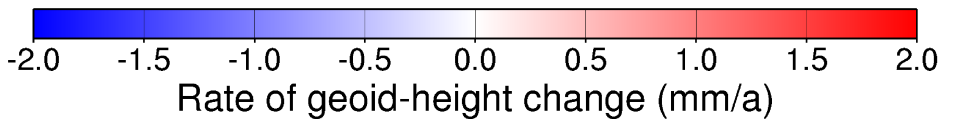

Figure 3: 
a)

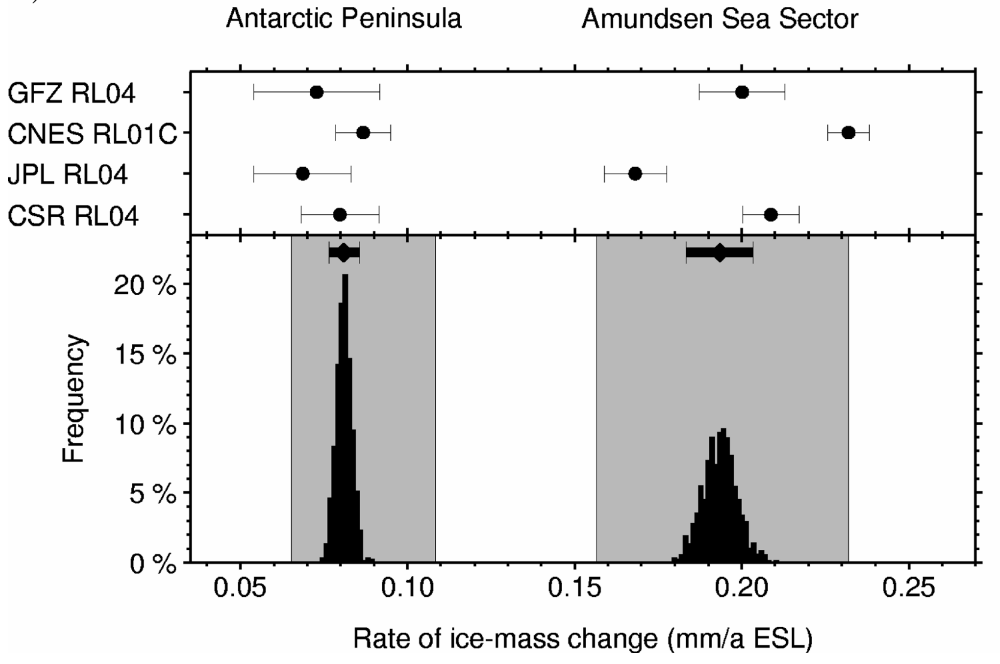

b)

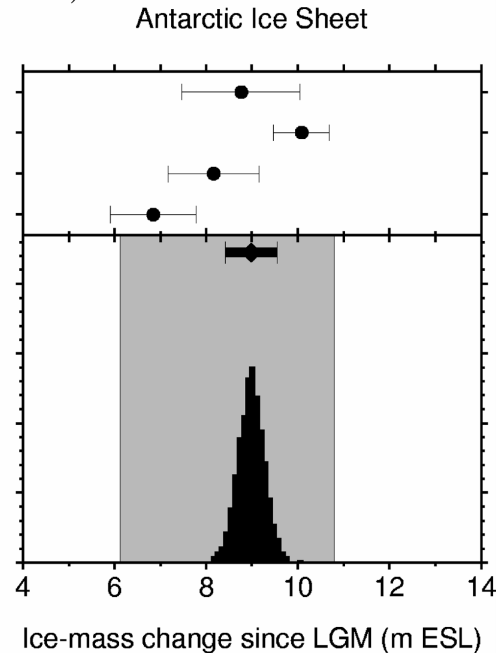

